Herz 2019 · 44:170-174

https://doi.org/10.1007/s00059-017-4663-1

Received: 28 July 2017

Revised: 19 November 2017

Accepted: 27 November 2017

Published online: 16 January 2018

(c) The Author(s) 2017. This article is an open access publication.

\section{CrossMark}

\section{P. Wang ${ }^{1} \cdot$ Y. Liu' $\cdot$ L. Ren' ${ }^{1}$}

'Department of Cardiology, Beijing Shijitan Hospital, Capital Medical University, Beijing, China

${ }^{2}$ Department of Ultrasound, Beijing Shijitan Hospital, Capital Medical University, Beijing, China

\section{Evaluation of left ventricular function after percutaneous recanalization of chronic coronary occlusions}

\author{
The role of two-dimensional speckle \\ tracking echocardiography
}

Chronic total occlusion (CTO) is defined as an occluded coronary artery presenting as thrombolysis in myocardial infarction (TIMI) with grade 0 or 1 flow in a recent myocardial infarction (MI) $[1,2]$. The myocardium in the perfusion territory of a CTO can be functional, dysfunctional but viable, or dysfunctional and nonviable $[3,4]$. Dysfunctional but viable myocardium in CTO may have restored function after percutaneous coronary intervention (PCI) [5-9]. However, the earliest time that the recovery of dysfunctional but viable myocardium can be detected remains unknown. Conventional echocardiography enables us to identify significant left ventricular (LV) dysfunction but not subclinical dysfunction [10]. Two-dimensional speckle tracking echocardiography (2D-STE) allows for an angle-independent evaluation of myocardial strain, and provides comprehensive information on LV myocardial contractility. Thus, 2DSTE is superior in detecting subtle deteriorations of contractility [11-13]. These advantages of 2D-STE are useful for the detection of subclinical recovery of dysfunctional but viable myocardium after CTO-PCI.

In this study, the LV systolic function of CTO patients with dysfunctional myocardium was evaluated at 1 day as well as 3 and 6 months after percutaneous revascularization using $2 \mathrm{D}$-STE. It was found that 2D-STE was superior in detecting subclinical LV systolic dysfunction in CTO patients after percutaneous revascularization.

\section{Patients and methods}

\section{Subjects}

A single-center prospective observational study was performed from July 2012 to March 2016. Patients with CTO with an estimated duration of less than 3 months or an MI during the previous 30 days were excluded, but no other predefined clinical inclusion or exclusion criteria were applied. The indication for PCI was determined by individual investigators at the participating center. In all, 43 patients (mean age: $66.09 \pm$ 10.99 years) scheduled to undergo PCI for CTO in a native coronary artery were eligible for enrollment. Among them, there were 40 males and three females. The CTO of ten patients was located in the left anterior descending artery in ten patients, in the right coronary artery in 25 patients, and in the circumflex artery in eight patients. A follow-up visit or telephone interview was scheduled at 1 day as well as 3 and 6 months after percutaneous revascularization. Prior written and informed consent was obtained from every patient. This study was approved by the Ethics Review Board of Capital Medical University.

\section{Percutaneous revascularization}

Percutaneous revascularization was performed by operators highly experienced in the treatment of CTO according to their standard practices with the femoral or brachial approach. The operation was considered successful when the residual stenosis was $\leq 30 \%$ of the intraluminal diameter, with TIMI grade 3 flow and no inhospital complications (death, acute myocardial infarction, or emergency coronary surgery). Clopidogrel (75 mg daily) was prescribed to all patients for at least 1 year after stent implantations, and aspirin was given indefinitely.

\section{Basic echocardiographic measurement and 2D-STE}

Echocardiography was performed using a Philips IE33 ultrasound machine (Koninklijke Philips N.V., The Netherlands) with an M4S transducer according to the recommendations of the American Society of Echocardiography $[4,13]$. The percentage of the left ventricular ejection fraction (LVEF) was calculated by Simpson's biplane method of discs.

The 2D echocardiography images (transmit/receive 1.9/4.0 MHz) were obtained from several views with frame 
rates of 30-90 frames/s. Digital data were stored and analyzed off-line. LV endocardial surface was traced manually, and the speckle tracking width was modified to cover the whole $\mathrm{LV}$ wall thickness so as to obtain curves for the peak longitudinal strain of: (a) the inferior septum and lateral wall in the apical four-chamber view (4C-PLS); (b) the inferior and anterior walls in the apical two-chamber view (2C-PLS); and (c) the inferior lateral and anterior septum in the apical three-chamber view (3C-PLS). LV global longitudinal systolic strain (GLS) was calculated by averaging the peak systolic values of the six LV walls. All the echocardiographic studies were performed by one echocardiographer. In terms of intraobserver variability, a sample of $2 \mathrm{D}$ strain was randomly selected and examined by the same observer in 2 days and the intraclass correlation coefficients were also calculated. All data were analyzed using Philips QLAB Advanced ultrasound quantification software (release 8.1).

\section{Statistical analysis}

The collected data were analyzed using the Statistical Package for Social Science (SPSS, version 19.0). Differences among groups were compared using the twotailed Student's $t$ test or chi-square analysis. Statistical significance was defined as a $p$ value of less than 0.05 .

\section{Results}

All the images of the 43 patients were suitable for analysis. Improvement of LVEF by CTO-PCI was observed at up to 3 and 6 months. The clinical characteristics of the 43 patients are listed in $\bullet$ Table 1 . The LVEF and GLS variables of all 43 patients before recanalization and at the followups are listed in $\bullet$ Table 2.

The 2D-STE revealed that GLS (Fig 1a, b) was significantly improved as early as 1 day after CTO-PCI (• Table 2).

These results indicated that 2D-STE could detect early subclinical LV systolic dysfunction in CTO patients after percutaneous revascularization.

Herz 2019 · 44:170-174 https://doi.org/10.1007/s00059-017-4663-1

(c) The Author(s) 2017. This article is an open access publication.

\author{
P. Wang · Y. Liu · L. Ren
}

\title{
Evaluation of left ventricular function after percutaneous recanalization of chronic coronary occlusions. The role of two- dimensional speckle tracking echocardiography
}

\section{Abstract}

Background. This study evaluated the feasibility of using two-dimensional speckle tracking echocardiography (2D-STE) to monitor left ventricular (LV) and overall function after percutaneous recanalization. Methods. LV function after percutaneous recanalization was monitored by 2D-STE and conventional echocardiography in 43 patients with coronary chronic total occlusion (CTO) who underwent primary percutaneous coronary intervention ( $\mathrm{PCI})$. Follow-ups were carried out 1 day as well as 3 and 6 months after CTO-PCI. At each time point, LV ejection fraction (LVEF) was examined by echocardiography, and LV global longitudinal strain (GLS) was measured by 2D-STE.
Results. It was found that the global longitudinal strain assessed with 2D-STE was improved as early as 1 day after CTO-PCI, whereas LVEF tended to improve up to 3 and 6 months after CTO-PCI.

Conclusion. $\mathrm{PCl}$ can effectively improve LV function in patients with CTO. 2D-STE is a superior technique for objectively quantifying the functional change earlier.

\section{Keywords}

Coronary occlusion - Echocardiography . Percutaneous coronary intervention $\cdot$ Left ventricular ejection fraction - Myocardial infarction

\section{Beurteilung der linksventrikulären Funktion nach perkutaner Rekanalisation chronischer Koronarverschlüsse. Bedeutung der 2-D-Speckle-Tracking-Echokardiographie}

\section{Zusammenfassung}

Hintergrund. Die vorliegende Studie befasst sich mit der Eignung der zweidimensionalen Speckle-Tracking-Echokardiographie (2DSTE) zur Überwachung der linksventrikulären (LV) und Gesamtfunktion nach perkutaner Rekanalisation.

Methoden. Die LV-Funktion nach perkutaner Rekanalisation wurde bei 43 Patienten mit koronarer chronischer Totalokklusion ("coronary chronic total occlusion", CTO), bei denen eine primäre perkutane Koronarintervention („percutaneous coronary intervention", $\mathrm{PCl}$ ) erfolgt war, mittels 2DSTE und herkömmlicher Echokardiographie überwacht. Nachuntersuchungen wurden einen Tag sowie 3 und 6 Monate nach CTO-PCI durchgeführt. Zu jedem Zeitpunkt wurde die LV-Ejektionsfraktion (LVEF) mittels Echokardiographie und die LV-
Gesamt-Longitudinaldeformation („,global longitudinal strain", GLS) mittels 2D-STE gemessen.

Ergebnisse. Die Autoren stellten fest, dass die mit 2D-STE erfasste GLS sich schon einen Tag nach CTO-PCI verbessert hatte, während die LVEF sich 3 bzw. 6 Monaten nach CTP-PCI allmählich besserte.

Schlussfolgerung. Eine $\mathrm{PCI}$ kann die LVFunktion bei Patienten mit CTO wirksam verbessern. Die 2D-STE erwies sich als überlegenes Verfahren für die frühzeitige objektive quantitative Beurteilung funktioneller Veränderungen

Schlüsselwörter

Koronarverschluss - Echokardiographie . Perkutane Koronarintervention - Linksventrikuläre Ejektionsfraktion · Myokardinfarkt

\section{Discussion}

This study found that the LVEF tended to improve at approximately 3 and 6 months after percutaneous revascularization in patients with CTO. Using 2D-STE, GLS was observed to be restored as early as 1 day after CTO-PCI. These results demonstrate that $2 \mathrm{D}-\mathrm{STE}$ is a reliable way to monitor early subclinical LV changes.

Myocardium in the perfusion territory of a CTO can be functional, dysfunctional but viable, or dysfunctional and nonviable [14-16]. The targeted area of heart tissues in CTO patients comprise hibernating myocardium [17]. Biopsies of hibernating myocardium always show 


$$
\begin{array}{llllll}
\bigcirc & \text { Long. Strain } & \bigcirc & \text { Transv. Strain } & \bigcirc & \text { Transv. Display } \\
\bigcirc & \text { circ. Strain } & \bigcirc & \text { Radial Strain } & \bigcirc & \text { Radial Display }
\end{array}
$$

\begin{tabular}{|c|c|c|c|c|c|}
\hline & \multicolumn{3}{|c|}{ Long. Strain (\%) } & \multicolumn{2}{|c|}{ Global Long. Strain $=-14.01 \%$} \\
\hline & \multicolumn{2}{|c|}{$\mathrm{SD} 16(\mathrm{~ms})=95.48$} & \multicolumn{2}{|c|}{$\mathrm{SD} 12(\mathrm{~ms})=101.69$} & $\mathrm{SD} 6(\mathrm{~ms})=86.56$ \\
\hline & \multicolumn{2}{|c|}{ Segment } & Peak Value & \multirow{2}{*}{\begin{tabular}{|c} 
Time to Peak \\
$355.90 \mathrm{~ms}$
\end{tabular}} & \multirow{3}{*}{$\begin{array}{c}\text { Delay } \\
-129.24 \mathrm{~ms}\end{array}$} \\
\hline & BA & & $-24.77 \%$ & & \\
\hline & $\mathrm{BI}$ & & $-18.87 \%$ & $485.13 \mathrm{~ms}$ & \\
\hline & BAS & (2) & $-23.17 \%$ & $351.92 \mathrm{~ms}$ & \multirow{2}{*}{$-61.64 \mathrm{~ms}$} \\
\hline & \multicolumn{2}{|l|}{ BIL } & $-14.51 \%$ & $413.56 \mathrm{~ms}$ & \\
\hline & \multicolumn{2}{|l|}{ BAL } & $-29.31 \%$ & $309.38 \mathrm{~ms}$ & \multirow{2}{*}{$-252.01 \mathrm{~ms}$} \\
\hline & BIS & (3) & $-12.03 \%$ & $561.39 \mathrm{~ms}$ & \\
\hline & MA & (7) & $-6.86 \%$ & $445.37 \mathrm{~ms}$ & \multirow{2}{*}{$123.27 \mathrm{~ms}$} \\
\hline & $\mathrm{Ml}$ & (10) & $-18.48 \%$ & $322.10 \mathrm{~ms}$ & \\
\hline & MAS & (8) & $-8.01 \%$ & $445.37 \mathrm{~ms}$ & \multirow{2}{*}{$109.35 \mathrm{~ms}$} \\
\hline & MII & (11) & $-21.06 \%$ & $336.01 \mathrm{~ms}$ & \\
\hline & MAI & (12) & $10.72 \%$ & $653.59 \mathrm{~ms}$ & $11240 \mathrm{~m}$ \\
\hline & MIS & (9) & $-19.96 \%$ & $340.11 \mathrm{~ms}$ & $313.48 \mathrm{~ms}$ \\
\hline & ApA & (13) & $-7.21 \%$ & $326.07 \mathrm{~ms}$ & $200 \mathrm{~ms}$ \\
\hline & Apl & (15) & $-24.33 \%$ & $322.10 \mathrm{~ms}$ & $3.98 \mathrm{~ms}$ \\
\hline & ApL & (16) & $-17.55 \%$ & $369.04 \mathrm{~ms}$ & (1) \\
\hline & ApS & (14) & $-12.07 \%$ & $327.04 \mathrm{~ms}$ & $42.00 \mathrm{~ms}$ \\
\hline a & Apex & (17) & $-10.73 \%$ & $299.44 \mathrm{~ms}$ & \\
\hline 0 & ng. Strain & 0 & Transv. Strain & Transv. Display & \\
\hline 0 & c. Strain & 0 & Radial Strain & Radial Display & \\
\hline
\end{tabular}

\begin{tabular}{|c|c|c|c|}
\hline \multicolumn{2}{|c|}{ Long. Strain (\%) } & \multicolumn{2}{|c|}{ Global Long. Strain $=-14.01 \%$} \\
\hline SD $16(\mathrm{~ms})=76.59$ & \multicolumn{2}{|c|}{$\mathrm{SD} 12(\mathrm{~ms})=84.57$} & $\mathrm{SD} 6(\mathrm{~ms})=63.31$ \\
\hline Segment & Peak Value & Time to Peak & \multirow{3}{*}{$\begin{array}{l}\text { Delay } \\
-129.24 \mathrm{~ms}\end{array}$} \\
\hline $\mathrm{BA} \quad(1)$ & $-24.77 \%$ & $355.90 \mathrm{~ms}$ & \\
\hline (4) & $-18.87 \%$ & $485.13 \mathrm{~ms}$ & \\
\hline BAS & $-23.17 \%$ & $351.92 \mathrm{~ms}$ & \multirow{2}{*}{$-61.64 \mathrm{~ms}$} \\
\hline BIL & $-14.51 \%$ & $413.56 \mathrm{~ms}$ & \\
\hline BAL & $-21.78 \%$ & $485.13 \mathrm{~ms}$ & \multirow{2}{*}{$157.07 \mathrm{~ms}$} \\
\hline BIS & $-25.23 \%$ & $328.06 \mathrm{~ms}$ & \\
\hline MA & $-6.86 \%$ & $445.37 \mathrm{~ms}$ & \multirow{2}{*}{$123.27 \mathrm{~ms}$} \\
\hline (10) & $-18.48 \%$ & $322.10 \mathrm{~ms}$ & \\
\hline MAS & $-8.01 \%$ & $445.37 \mathrm{~ms}$ & \multirow{2}{*}{$109.35 \mathrm{~ms}$} \\
\hline (11) & $-21.06 \%$ & $336.01 \mathrm{~ms}$ & \\
\hline (12) & $-27.51 \%$ & $330.05 \mathrm{~ms}$ & \multirow{2}{*}{$157.07 \mathrm{~ms}$} \\
\hline MIS & $6.05 \%$ & $172.98 \mathrm{~ms}$ & \\
\hline ApA & $-7.21 \%$ & $326.07 \mathrm{~ms}$ & \multirow{2}{*}{$3.98 \mathrm{~ms}$} \\
\hline (15) & $-24.33 \%$ & $322.10 \mathrm{~ms}$ & \\
\hline ApL & $-24.15 \%$ & $320.11 \mathrm{~ms}$ & \multirow{2}{*}{$3.98 \mathrm{~ms}$} \\
\hline ApS & $-7.02 \%$ & $316.13 \mathrm{~ms}$ & \\
\hline Apex (17) & $-11.15 \%$ & $298.24 \mathrm{~ms}$ & \\
\hline
\end{tabular}

Peak Value
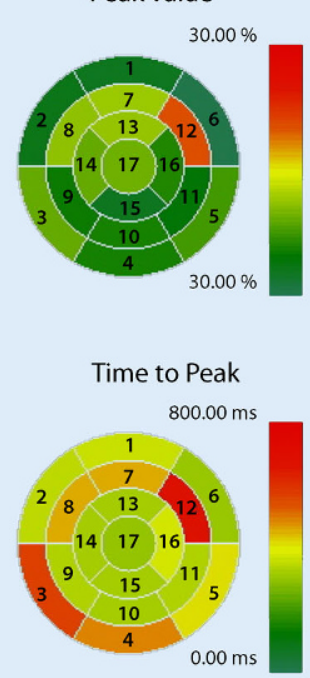

Peak Value

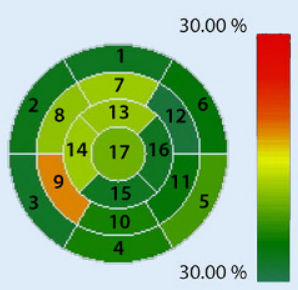

Time to Peak

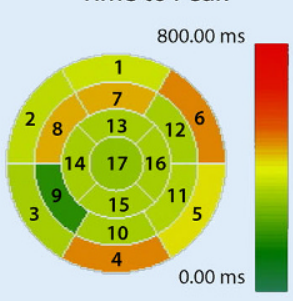

Fig. 1 Significant improvement in global longitudinal strain (GLS) after percutaneous coronary intervention (PCI). a GLS = $-14.01,1$ day before $\mathrm{PCI}$. b GLS $=-15.03,1$ day after PCl. Circ. circular, Long. longitudinal, Trans. transverse, $B A$ basal anterior, $B /$ basal inferior, $B A S$ basal anteroseptal, BIL basal inferolateral, MA mid anterior, $M /$ mid inferior, MASmid anteroseptal, MII mid inferolateral, MAI mid anterolateral, MIS mid inferoseptal, ApA apical anterior, Apl apical inferior, $A p L$ apical lateral, $A p S$ apical septal defects in nearly all cells [18]. The pathological changes include loss of sarcomeres and myofibrils in the center of the cells, absence of contractile material in the perinuclear areas, and presence of cellular debris in the enlarged extracellular space [19]. Vanoverschelde et al. found a relation between the extent of structural changes and the rate of recovery using myocardial biopsies [20]. The dysfunctional heart tissue in CTO patients can be improved after revascular- ization [21]. Steg and colleagues found that the recovery time of dysfunctional myocardium is dependent on the extent of damage at the cellular level, which is affected by different factors such as the duration and severity of ischemia [22]. However, more sensitive techniques are needed to assess the recovery of dysfunctional myocardium.

In this research, improvement of LVEF was observed for up to 3 and 6 months. However, by 2D-STE, the GLS improve- ment was observed as early as 1 day after CTO-PCI. 2D-STE is an automated and quantitative technique for the measurement of cardiac mechanics, which is based on the speckle interference of ultrasound beams within tissues. Speckles are tracked on a frame-by-frame basis throughout the cardiac cycle [23], which has more advantages than conventional echocardiography, including angle independency, free of tethering and transla- 


\begin{tabular}{|c|c|}
\hline Variable & Value \\
\hline Men & 40 \\
\hline Mean age (years) & $66.09 \pm 10.99$ \\
\hline LVEDD (mm) & $46 \pm 2$ \\
\hline $\operatorname{LVESD}(\mathrm{mm})$ & $29 \pm 3$ \\
\hline IVS thickness (mm) & $10.7 \pm 2.1$ \\
\hline PW thickness (mm) & $10.5 \pm 2.3$ \\
\hline LA diameter (mm) & $42 \pm 2$ \\
\hline RA diameter (mm) & $29 \pm 3$ \\
\hline \multicolumn{2}{|c|}{$\begin{array}{l}\text { LVEDD left ventricular end-diastolic dimen- } \\
\text { sion, } L V E S D \text { left ventricular end-systolic } \\
\text { dimension, IVS interventricular septum, } P W \\
\text { post wall, } L A \text { left atrium, } R A \text { right atrium }\end{array}$} \\
\hline
\end{tabular}

tion effects, low signal-to-noise ratio, and low measurement variability [24, 25].

Systolic dysfunction might initially appear in the longitudinal direction, as the longitudinally oriented subendocardial fibers are more vulnerable to myocardial ischemia and fibrosis. GLS correlates well with EF measured by echocardiography, and GLS is a superior predictor of outcome compared with LVEF [26]. The EF measured by conventional echocardiography could show radial and partly longitudinal functions, whereas GLS could indicate longitudinal function.

\section{Limitations}

There are several limitations in this study. There was a lack of control patients without intervention. Drug and other treatments may synergize the effects of revascularization on LV function. Only three time points were used in the follow-ups. More time points should be included to describe continuous improvement of heart function.

\section{Conclusion}

$\mathrm{PCl}$ treatment can effectively improve LV function in patients with CTO. The results of this study provide evidence to support the clinical use of 2D-STE to monitor the early changes of LV function.

Table 2 LVEF and GLS variables of the 43 patients before $\mathrm{PCl}$ and at follow-up

\begin{tabular}{lllll} 
& LVEF & $\boldsymbol{p}$ & GLS & $\boldsymbol{p}$ \\
\hline PRO & $59.35 \pm 10.16$ & - & $-13.25 \pm 1.86$ & - \\
\hline 1 Day & $60.35 \pm 10.48$ & $0.112^{\mathrm{a}}$ & $-14.54 \pm 2.06$ & $<0.001^{\mathrm{a}}$ \\
\hline 3 Months & $61.95 \pm 10.20$ & $<0.001^{\mathrm{b}}$ & $-15.51 \pm 2.05$ & $<0.001^{\mathrm{b}}$ \\
\hline 6 Months & $65.86 \pm 9.83$ & $<0.001^{\mathrm{c}}$ & $-16.58 \pm 2.17$ & $<0.001^{\mathrm{c}}$
\end{tabular}

LVEF left ventricular ejection fraction, $P R O$ preoperative, PEF preoperative ejection fraction, GLS global longitudinal strain, $P G$ preoperative global longitudinal strain

${ }^{\text {a}}$ Preoperative vs. at 1 day

${ }^{\text {b}}$ Preoperative vs. at 3 months

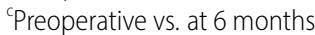

\section{Corresponding address}

\section{Ren}

Department of Cardiology, Beijing Shijitan

Hospital, Capital Medical University

No. 10 Tieyi Road, 100038 Beijing, China

renlihui1970@hotmail.com

Acknowledgements. This work was supported by Capital Clinical characteristics of applied research projects (grant no. Z171100001017043), and Beijing Municipal Administration of Hospitals Incubating Program (grant no. PX2016023).

\section{Compliance with ethical guidelines}

Conflict of interest. P. Wang, Y. Liu, and L. Ren declare that they have no competing interests.

All procedures followed were in accordance with the ethical standards of the responsible committee on human experimentation (institutional and national) and with the Helsinki Declaration of 1975 (in its most recently amended version). Informed consent was obtained from all patients included in the study.

Open Access This article is distributed under the terms of the Creative Commons Attribution 4.0 International License (http://creativecommons.org/licenses/by/ 4.0/), which permits unrestricted use, distribution, and reproduction in any medium, provided you give appropriate credit to the original author(s) and the source, provide a link to the Creative Commons license, and indicate if changes were made.

\section{References}

1. Sun D, Wang J, Tian Y, Narsinh K, Wang H, Li C et al (2012) Multimodality imaging evaluation of functional and clinical benefits of percutaneous coronary intervention in patients with chronic total occlusion lesion. Theranostics 2(8):788-800

2. Pancholy SB, Boruah P, Ahmed I, Kwan T, Patel TM, Saito S (2013) Meta-analysis of effect on mortality of percutaneous recanalization of coronary chronic total occlusions using a stent-based strategy. Am J Cardiol 111(4):521-525

3. Katsube Y, Saro H, Naka M, Kim BH, Kinoshita N, Koretsune $Y$ et al (1996) Decreased baroreflex sensitivity in patients with stable coronary artery disease is correlated with the severity of coronary narrowing. Am J Cardiol 78(9):1007-1010

4. Melchior JP, Doriot PA, Chatelain P, Meier B, Urban P, Finci L et al (1987) Improvement of left ventricular contraction and relaxation synchronism after recanalization of chronic total coronary occlusion by angioplasty. J Am Coll Cardiol 9(4):763-768

5. La Rovere MT, Bigger JT Jr., Marcus Fl, Mortara A, Schwartz PJ (1998) Baroreflex sensitivity and heart-rate variability in prediction of total cardiac mortality after myocardial infarction. ATRAMI (Autonomic Tone and Reflexes After Myocardial Infarction) investigators. Lancet 351(9101):478-484

6. La Rovere MT, Pinna GD, Hohnloser SH, Marcus Fl, Mortara A, Nohara R et al (2001) Baroreflex sensitivity and heart rate variability in the identification of patients at riskfor life-threatening arrhythmias: implications for clinical trials. Circulation 103(16):2072-2077

7. Bonnemeier H, Hartmann F, Wiegand UK, Irmer C, Kurz T, Tolg R et al (2000) Heart rate variability in patients with acute myocardial infarction undergoing primary coronary angioplasty. Am J Cardiol 85(7):815-820

8. Szwoch M, Ambroch-Dorniak K, Sominka D, DorniakW, Danilowicz-Szymanowicz L, Krassowski $W$ et al (2009) Comparison the effects of recanalisation of chronic total occlusion of the right and left coronary arteries on the autonomic nervous system function. Kardiol Pol 67(5):467-474

9. Danilowicz-Szymanowicz L, Ambroch-Dorniak K, Dorniak W, Szwoch M, Fabiszak D, Sominka D et al (2008) Early effects of recanalization of a chronically occluded coronary artery on autonomic nervous system activity. Pol Merkur Lekarski 25(148):315-319

10. Steigen TK, Buller CE, Mancini GB, Jorapur V, Cantor WJ, Rankin JM et al (2010) Myocardial perfusion grade after late infarct artery recanalization is associated with global and regional left ventricular function at one year: analysis from the Total Occlusion Study of Canada-2. Circ Cardiovasc Interv 3(6):549-555

11. Stanton T, Leano R, Marwick TH (2009) Prediction of all-cause mortality from global longitudinal speckle strain: comparison with ejection fraction 


\section{Original articles}

and wall motion scoring. Circ Cardiovasc Imaging 2(5):356-364

12. Notomi $Y$, Lysyansky $P$, Setser RM, Shiota $T$, Popovic ZB, Martin-Miklovic MG et al (2005) Measurement of ventricular torsion by twodimensional ultrasound speckle tracking imaging. J Am Coll Cardiol 45(12):2034-2041

13. Geyer H, Caracciolo G, Abe H, Wilansky S, Carerj S, Gentile F et al (2010) Assessment of myocardial mechanics using speckle tracking echocardiography: fundamentals and clinical applications. JAm SocEchocardiogr23(4):351-369

14. Olivari Z, Rubartelli P, Piscione F, Ettori F, Fontanelli A, Salemme L et al (2003) Immediate results and one-year clinical outcome after percutaneous coronary interventions in chronic total occlusions: data from a multicenter, prospective, observational study (TOAST-GISE). J Am Coll Cardiol 41(10):1672-1678

15. Prasad A, Rihal CS, Lennon RJ, Wiste HJ, Singh M, Holmes DR Jr. (2007) Trends in outcomes after percutaneous coronary intervention for chronic total occlusions: a 25-year experience from the Mayo Clinic. J Am Coll Cardiol 49(15):1611-1618

16. Suero JA, Marso SP, Jones PG, Laster SB, Huber KC, Giorgi LV et al (2001) Procedural outcomes and long-term survival among patients undergoing percutaneous coronary intervention of a chronic total occlusion in native coronary arteries: a 20year experience. J Am Coll Cardiol 38(2):409-414

17. Kirschbaum SW, Baks T, van den Ent M, Sianos G, Krestin GP, Serruys PW et al (2008) Evaluation of left ventricularfunction threeyears afterpercutaneous recanalization of chronic total coronary occlusions. Am J Cardiol 101(2):179-185

18. White HD, Braunwald E (1998) Applying the open artery theory: use of predictive survival markers. Eur Heart J 19(8):1132-1139

19. Monteiro P, Antunes A, Goncalves LM, Providencia LA (2003) Long-term clinical impact of coronarycollateral vessels after acute myocardial infarction. Rev Port Cardiol 22(9):1051-1061

20. Vanoverschelde JL, Depre C, Gerber BL, Borgers M, Wijins W, Robert A et al (2000) Time course of functional recovery after coronary artery bypass graft surgery in patients with chronic left ventricular ischemic dysfunction. Am J Cardiol 85(5):1432-1439

21. Joyal D, Afilalo J, Rinfret S (2010) Effectiveness of recanalization of chronic total occlusions: a systematic review and meta-analysis. Am Heart J 160(1):179-187

22. Steg PG, Thuaire C, HimbertD, CarrieD, Champagne S, Coisne D et al (2004) DECOPI (DEsobstructionCOronaireen Post-Infarctus): a randomized multicentre trial of occluded artery angioplasty after acute myocardial infarction. Eur Heart J 25(24):2187-2194

23. Haas $F$, Jennen L, Heinzmann U, Augustin N, Wottke M, Schwaiger M et al (2001) Ischemically compromised myocardium displays different time-courses of functional recovery: correlation with morphological alterations? Eur J Cardiothorac Surg 20(2):290-298

24. Korinek J, Wang J, Sengupta PP, Miyazaki C, Kjaergaard J, McMahon E et al (2005) Twodimensional strain - a Doppler-independent ultrasound method for quantitation of regional deformation: validation in vitro and in vivo. J Am Soc Echocardiogr 18(12):1247-1253

25. Kempny A, Diller GP, Kaleschke G, Orwat S, Funke A, Radke Ret al (2013) Longitudinal left ventricular $2 D$ strain is superior to ejection fraction in predicting myocardial recovery and symptomatic improvement after aortic valve implantation. Int J Cardiol 167(5):2239-2243

26. Staron A, Bansal M, Kalakoti P, Nakabo A, Gasior $Z$, Pysz P et al (2013) Speckle tracking echocardiography derived 2-dimensional myocardial strain predicts left ventricular function and mass regression in aortic stenosis patients undergoing aortic valve replacement. Int J Cardiovasc Imaging 29(4):797-808

\section{Hier steht eine Anzeige.}

\section{Springer}

